American Journal of Pharmaceutical Education 2021; 85 (1) Article 7990.

\title{
RESEARCH
}

\section{Effect of Changing From Closed-Book to Formulary-Allowed Examinations}

\author{
Daniel T. Malone, PhD, Sara Chuang, PhD, MPharm, Elizabeth Yuriev, PhD, Jennifer L. Short, PhD \\ Monash University, Faculty of Pharmacy and Pharmaceutical Sciences, Parkville, Australia \\ Submitted January 19, 2020; accepted September 11, 2020; published January 2021.
}

Objective. To determine whether allowing final-year Bachelor of Pharmacy students to use a medicines formulary during examinations modified their learning behaviors and performance, and to investigate students' perceptions about having this resource available during examinations.

Methods. Student performance and examination difficulty (as measured by classification of examination questions as high or low according to Bloom's taxonomy of learning) in second semester examinations (formulary allowed) was compared with first semester examinations (closed book) in successive years. Students completed a survey regarding their study and examination approaches and experiences after both semesters.

Results. Examinations in semester two had more questions rated higher on Bloom's taxonomy than did examinations in semester one. Data were collected from student surveys for closed book examinations (response rate of 25\% and 19\% in 2015 and 2016, respectively) and open book examinations (response rate of $22 \%$ and 15\% in 2015 and 2016, respectively). Students' study approaches, hours studied per week, and anxiety (all self-reported) did not differ between semesters one and two, but students in semester two spent more time studying with a formulary compared with students in semester one. Qualitative analysis of student comments revealed students preferred the formulary-allowed examinations over the closed-book examinations. The majority of students $(68 \%)$ agreed with the statement: "Knowing that I will have access to the AMH [Australian Medicines Handbook] during the exams allowed me to pay more attention to higher level skills such as analysis and evaluation."

Conclusion. When students were allowed to use a formulary for examinations, they studied more using their formulary prior to the examination. Students performed similarly on examinations with a greater proportion of questions addressing higher levels of Bloom's taxonomy and on closed-book examinations that were comparatively less cognitively challenging.

Keywords: open-book examinations, higher education, assessment, formulary, pharmacy students

\section{INTRODUCTION}

Open-book examinations can be defined as assessments for which the use of textbooks, notes, journals, and/ or other reference materials are allowed. ${ }^{1}$ While openbook examinations have existed for many years, ${ }^{2,3}$ the use of such examinations as summative assessments in multiple courses in undergraduate pharmacy degrees, to the best of our knowledge, has not been assessed. Reported benefits of open-book examinations include a reduced anxiety level, decreased emphasis on rote memorization, ${ }^{4}$ the encouragement of "a deeper engagement with the course material on the part of the students," 5 and "thinking at higher cognitive levels."1 Moreover, an open-book examination may enhance student understanding in a

Corresponding Author: Daniel T. Malone, Monash University, Faculty of Pharmacy and Pharmaceutical Sciences, 381 Royal Pde., Parkville, 3052, Australia. Tel: +61-3-9903-9576. Email: dan.malone@monash.edu more realistic context rather than just recalling facts ${ }^{6}$ and more closely typifies the experience of real-life health practitioners who commonly refer to resources in order to make clinical decisions. ${ }^{7}$ Considering the exponential increase in health and clinical knowledge, it is especially important that students are able to apply knowledge from reputable sources, such as medicines formularies. ${ }^{8-10}$

Prior to 2015, with the exception of one capstone course, all end-of-semester examinations in the Faculty of Pharmacy and Pharmaceutical Sciences at Monash University, Australia, were closed-book. In 2015, students were allowed to bring a medicines formulary (the Australian Medicines Handbook or $A M H$ ) into all second semester, fourth year, end-of-semester examinations. Since 1998, the $A M H$ has been an independent and up-todate source of medicines information for the use of health care professionals. The $A M H$ contains abbreviated monographs on prescription and non-prescription medicines and is one of the main recommended texts for intern 


\section{American Journal of Pharmaceutical Education 2021; 85 (1) Article 7990.}

and registered pharmacists in Australia. We hypothesized that allowing students to bring a formulary into examinations would encourage deeper engagement with the material as opposed to rote learning and allow course coordinators to construct examination questions that were at a higher cognitive level.

This study sought to investigate the effects of permitting the use of the $A M H$ on student study behaviors, perceptions, and examination performance. Specifically, the primary aim was to determine whether allowing $A M H$ use in examinations improved student learning, A secondary aim was to determine whether student self-reported learning behaviors were changed when students knew they would have access to an $A M H$ during an examination.

\section{METHODS}

The Bachelor of Pharmacy program at Monash University is a four-year degree program. There are two 12 -week semesters in a year and four courses (termed "units" at Monash University) are studied per semester. In the first semester of the fourth year in 2015 and 2016, students undertook three courses that each culminated in an end-of-semester examination as well as an experiential placement (termed a professional experience placement or PEP) that was marked as pass or fail only. The three first semester courses covered topics such as drug delivery and development, therapeutics of endocrine and renal, and therapeutics of dermatology and pain. In the second semester, there were four courses each with an end-of-semester examination (Table 1). The four second-semester courses covered topics such as medication management/ legislation, clinical decision making, therapeutics of neurology and oncology, and therapeutics of mental health. End-of-semester examinations in the fourth year were worth $45 \%-60 \%$ of the overall course grade, and students had to achieve a grade of at least $50 \%$ to pass each course.

Table 1. Examination Performance Before and After Allowing Pharmacy Students to Use a Medicines Formulary During Examinations

\begin{tabular}{|c|c|c|c|c|c|}
\hline \multirow[b]{2}{*}{ Course } & \multicolumn{2}{|c|}{$\begin{array}{l}\text { Closed-Booked } \\
\text { Examinations } \\
\text { (Semester 1), } \\
\text { Mean } \pm \text { SEM }\end{array}$} & \multicolumn{3}{|c|}{$\begin{array}{l}\text { Open-Book Examinations } \\
\text { (Semester 2), Mean } \pm \text { SEM }\end{array}$} \\
\hline & 2015 & 2016 & Course & 2015 & 2016 \\
\hline 1 & $70 \pm 1$ & $72 \pm 1$ & 4 & $67 \pm 1$ & $67 \pm 1$ \\
\hline 2 & $68 \pm 1$ & $67 \pm 1$ & 5 & $68 \pm 1$ & $67 \pm 1$ \\
\hline \multirow[t]{2}{*}{3} & $67 \pm 1$ & $69 \pm 1$ & 6 & $62 \pm 1$ & $63 \pm 1$ \\
\hline & & & 7 & $89 \pm 1$ & $89 \pm 1$ \\
\hline
\end{tabular}

The three end-of-semester examinations administered during semester one in 2015 and semester one in 2016 were closed-book examinations. In semester two of 2015 and 2016, students were allowed to refer to an $A M H$ medicines formulary (current version of $A M H$ or version from previous year) during examinations. Students were informed at the start of semester two that for all examinations for the upcoming semester, they were allowed to use a "clean" $A M H$ (that is, an $A M H$ with no additional markings, inserts, stickers, or other components).

All examinations contained a mix of multiple-choice questions (MCQs) and short-answer questions. All examinations went through a quality assurance process that involved checking for constructive alignment and question difficulty by a person with experience in the examination content that was not the collator of the examination. No specific directive was given to course coordinators to alter question types except for a discussion prior to semester two announcing that students would have access to an $A M H$ during all of their semester two examinations. For each examination, MCQ analytics were checked, including percentage of students that got each question correct and the discrimination index. When these parameters were low, a decision was made as to whether to exclude the question from the examination. For shortanswer questions, the average number of points received for each question was reviewed. No questions were omitted from 2015 and 2016 fourth-year examinations. Examinations varied in length from two to three hours as well as in terms of number of questions. All assessments were externally checked by a person from another Australian University as part of a standard course review process, and no issues with the examinations from 2015 and 2016 were identified.

A mixed methods approach was adopted whereby student examination performance and assessment item difficulty were compared for fourth year end-of-semester examinations with and without the $\mathrm{AMH}$, ie, semester two vs semester one. After the conclusion of both examination periods, students were asked to complete a survey on their study and examination habits and to comment on their experiences studying for and taking formulary-allowed and closed-book examinations. The study was approved by Monash University's Human Research and Ethics Committee. Students provided informed consent through Moodle (moodle.org), the online learning management system used by Monash University, and were informed that completing the survey would not impact their grades in the fourth-year courses in which they were enrolled. The survey was divided into four main sections: general questions about the student's age and gender (Table 2); questions about how many hours per week the student 


\section{American Journal of Pharmaceutical Education 2021; 85 (1) Article 7990.}

Table 2. Cohort Age and Gender Demographics, and Self-reported Hours of Study per Week Before and After Allowing Pharmacy Students to Use a Medicines Formulary During Examinations

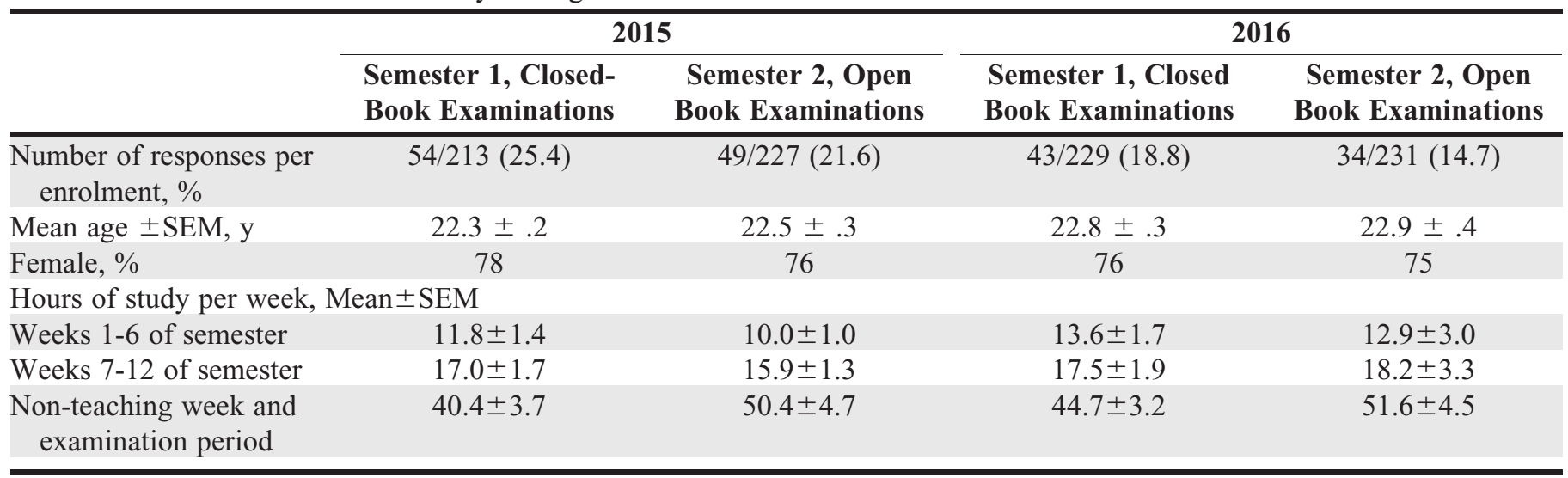

studied in the first half (weeks 1-6) of the semester, the second half (weeks 7-12) of the semester, and at the conclusion of the semester in preparation for the examination period (up to four weeks from the end of semester to the end of the examination period; Table 2); statements about study approaches, which were taken from the Revised Two-factor Study Process Questionnaire (R-SPQ-2F) developed by Biggs and colleagues ${ }^{11}$ (Table 3); and statements about student examination experiences and perceptions about studying with the $A M H$ (Table 4). Three additional statements relating to student perceptions of the use of the AMH during the examinations were included in the survey following the semester two examination period (refer to statements 10-12 in Table 4).

Sections three and four of the survey were based on a five-point Likert scale on which $1=$ not at all, $2=$ to a small extent, $3=$ somewhat, $4=$ to a large extent, and $5=$ all the time. In sections two, three, and four of the survey, students were asked to comment on their responses provided in the previous sections because when student responses are volunteered in an unstructured

Table 3. Self-reported Student Study Approaches Before and After Allowing Pharmacy Students to Use a Medicines Formulary During Examinations

\begin{tabular}{|c|c|c|c|c|c|}
\hline & \multirow[b]{2}{*}{ Semester } & \multicolumn{2}{|c|}{2015} & \multicolumn{2}{|c|}{2016} \\
\hline & & Mean \pm S.E.M. & Cronbach alpha & Mean \pm S.E.M. & Cronbach alpha \\
\hline \multirow[t]{2}{*}{ Deep Motive } & 1 & $3.0 \pm .6$ & .8 & $3.0 \pm .5$ & 8 \\
\hline & 2 & $2.8 \pm .5$ & .7 & $2.9 \pm .6$ & .9 \\
\hline \multirow{2}{*}{ Deep Strategy } & 1 & $2.9 \pm .5$ & .8 & $2.9 \pm .5$ & .7 \\
\hline & 2 & $2.8 \pm .4$ & .6 & $2.7 \pm .6$ & .8 \\
\hline \multirow[t]{2}{*}{ Deep Approach } & 1 & $3.0 \pm 1.0$ & .9 & $2.9 \pm 1.0$ & .9 \\
\hline & 2 & $2.8 \pm .8$ & .8 & $2.8 \pm 1.2$ & .9 \\
\hline \multirow[t]{2}{*}{ Surface Motive } & 1 & $2.2 \pm .5$ & .7 & $2.2 \pm .6$ & .8 \\
\hline & 2 & $2.2 \pm .5$ & .7 & $2.4 \pm .7$ & .8 \\
\hline \multirow[t]{2}{*}{ Surface Strategy } & 1 & $2.9 \pm .5$ & .6 & $2.8 \pm .6$ & .8 \\
\hline & 2 & $3.2 \pm .5$ & .6 & $3.0 \pm .6$ & .7 \\
\hline \multirow[t]{2}{*}{ Surface Approach } & 1 & $2.6 \pm 1.0$ & .8 & $2.5 \pm 1.1$ & .9 \\
\hline & 2 & $2.7 \pm 0.9$ & .8 & $2.7 \pm 1.2$ & .9 \\
\hline
\end{tabular}

$1=$ This item is never or only rarely true of me,

$2=$ This item is sometimes true of me,

$3=$ This item is true of me about half the time,

$4=$ This item is frequently true of me,

$5=$ This item is always or almost always true of me.

2015: $\mathrm{N}=50$ for semester 1 (closed book examinations) and 44 for semester 2 (open book examinations).

2016: $\mathrm{N}=35$ for semester 1 (closed book examinations) and 13 for semester 2 (open book examinations) 


\section{American Journal of Pharmaceutical Education 2021; 85 (1) Article 7990.}

Table 4. Student Experiences of Examinations and Perceptions of Studying with the AMH Before and After Allowing Pharmacy Students to Use a Medicines Formulary During Examinations ( $\mathrm{N}=48$ for semester 1 and 43 for semester 2)

\begin{tabular}{|c|c|c|c|c|c|}
\hline \multirow[b]{2}{*}{ Statement Type } & \multirow[b]{2}{*}{ Statement } & \multicolumn{2}{|c|}{$\begin{array}{c}\text { Closed } \\
\text { Book } \\
\text { Examinations } \\
\text { (Semester 1) }\end{array}$} & \multicolumn{2}{|c|}{$\begin{array}{c}\text { Open Book } \\
\text { Examinations } \\
\text { (Semester 2) }\end{array}$} \\
\hline & & 2015 & 2016 & 2015 & 2016 \\
\hline \multirow[t]{6}{*}{ Examination satisfaction } & 1. The exams were intellectually challenging & 4.1 & 3.8 & 4.1 & 4.2 \\
\hline & $\begin{array}{l}\text { 2. The exams aligned well with the learning } \\
\text { outcomes of the unit (course) }\end{array}$ & 3.9 & 3.7 & 3.6 & 3.6 \\
\hline & $\begin{array}{l}\text { 3. The exam questions allowed me to } \\
\text { demonstrate my knowledge (command) of } \\
\text { the topic }\end{array}$ & 3.6 & 3.5 & 3.5 & 3.9 \\
\hline & $\begin{array}{l}\text { 4. The format of the exam questions was } \\
\text { relevant to pharmacy }\end{array}$ & 3.7 & 3.5 & 3.6 & 4.0 \\
\hline & 5. The exam questions were engaging & 3.6 & 3.4 & 3.4 & 3.6 \\
\hline & Cronbach alpha & .7 & .8 & .6 & .3 \\
\hline \multirow[t]{3}{*}{ Open book exam preference } & 6. I prefer open book to closed book exams & 3.1 & 3.0 & 3.3 & 3.5 \\
\hline & $\begin{array}{l}\text { 7. I prefer closed book exams to AMH allowed } \\
\text { exams }\end{array}$ & - & - & 2.2 & 2.6 \\
\hline & Cronbach alpha & - & - & .8 & .6 \\
\hline \multirow[t]{3}{*}{ Anxiety } & $\begin{array}{l}\text { 8. I felt anxious about the exams during the } \\
\text { semester }\end{array}$ & 3.7 & 3.4 & 3.6 & 3.7 \\
\hline & $\begin{array}{l}\text { 9. I felt anxious about the exams just prior to } \\
\text { taking them }\end{array}$ & 3.9 & 3.8 & 3.9 & 4.2 \\
\hline & Cronbach alpha & .8 & .8 & .7 & .8 \\
\hline Refer to AMH during study & $\begin{array}{l}\text { 10. During my study, I frequently referred to an } \\
\text { Australian Medicines Handbook (AMH) }\end{array}$ & 3.3 & 3.2 & $3.9^{\mathrm{b}}$ & $4.4^{\mathrm{a}}$ \\
\hline \multirow[t]{4}{*}{$\begin{array}{l}\text { AMH examinations testing } \\
\text { higher cognitive levels }\end{array}$} & $\begin{array}{l}\text { 11. Knowing that I will have access to the AMH } \\
\text { during the exam allowed me to pay less } \\
\text { attention to remembering specific facts }\end{array}$ & - & - & 3.6 & 3.9 \\
\hline & $\begin{array}{l}\text { 12. Knowing that I will have access to the AMH } \\
\text { during the exams allowed me to pay more }\end{array}$ & - & - & 4.1 & 3.8 \\
\hline & attention to higher level skills such as & & & & \\
\hline & analysis and evaluation & & & 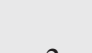 & \\
\hline & Cronbach alpha & - & - & .3 & .7 \\
\hline
\end{tabular}

Self-reported examination experience means, based on a five-point Likert scale: $1=$ Not at all, $2=$ To a small extent, $3=$ Somewhat, $4=$ To a large extent, $5=$ All the time.

Indicates a significant difference compared with first semester of the same year $\left({ }^{\mathrm{a}} p<.05,{ }^{\mathrm{b}} p<.01\right)$.

(2015: $\mathrm{N}=50$ for semester 1 and 44 for semester 2, 2016: $\mathrm{N}=35$ for semester 1 and 13 for semester 2).

Cronbach alpha values were calculated when there was more than one statement per statement type

way, they may reflect a more student-centred perspective of their experience. ${ }^{12}$ Thematic analysis methods were used to identify and report on common themes in the data. ${ }^{11}$

Data were entered into NVivo, version 12 (QSR International, Burlington, MA) qualitative analysis software. Following the guidelines of Braun and Clarke, ${ }^{13}$ analysis of data was divided into six phases. In the first phase, the lead investigator (DTM) produced initial nodes by reading and rereading student statements (familiarization). In the second phase (initial coding), four investigators independently assigned sections of text to descriptive nodes. New nodes were identified. Once all data were coded and collated, the authors sorted nodes into overarching themes (phase 3: theme identification). In phase 4 (theme review), the candidate themes were refined, removed, merged, or divided, as needed.

The final themes defined were study, exams, and role of the $A M H$ (phase 5: defining and naming themes). To ensure rigour, the student data were re-coded by using the agreed upon themes (phase 6: final analysis). Full sentences were coded to the nodes, and if the sentence related to 
American Journal of Pharmaceutical Education 2021; 85 (1) Article 7990.

Table 5. Themes, Subthemes and Representative Quotes

\begin{tabular}{|c|c|c|}
\hline Theme & Subtheme & Participant Quotes \\
\hline \multirow[t]{3}{*}{ Exams } & Negative aspects & "They do not allow me to show my full understanding" \\
\hline & Positive aspects & $\begin{array}{l}\text { "Case-study based questions were great and definitely } \\
\text { challenged me in a real way that I felt was significant and } \\
\text { relevant to pharmacy practice" }\end{array}$ \\
\hline & Thoughts of exam content & $\begin{array}{l}\text { "It was good that many of the questions were based off case } \\
\text { studies or relevant to our knowledge to understand the } \\
\text { subject at a higher level" }\end{array}$ \\
\hline \multirow[t]{3}{*}{ Study } & Approaches to learning & $\begin{array}{l}\text { "The only limit on studying is time. If I have less time, this } \\
\text { means I have to compromise and learn/route (sic) learn } \\
\text { information that I believe would be on the exam" }\end{array}$ \\
\hline & Quantity and justification & $\begin{array}{l}\text { "I study more during end of semester (near exam period) and } \\
\text { during mid semester break" }\end{array}$ \\
\hline & & $\begin{array}{l}\text { "Unfortunately, I spent most of the second half semester } \\
\text { practicing on interview questions and applying for internship } \\
\text { positions which is why I studied less" }\end{array}$ \\
\hline \multirow[t]{3}{*}{ Role of AMH } & How AMH was used & $\begin{array}{l}\text { "During semester I study by making summaries and in the } \\
\text { exam period I re-read my summaries, read lecture notes and } \\
\text { textbooks (including AMH) and do practice questions" }\end{array}$ \\
\hline & Negative aspects & $\begin{array}{l}\text { "The AMH deterred students from expressing what they knew } \\
\text { but instead relayed information found in the AMH. Students } \\
\text { who utilised the AMH were able to do better than those who } \\
\text { simply memorised and studied the lecture material" }\end{array}$ \\
\hline & Positive aspects & $\begin{array}{l}\text { "The use of an AMH in the exam, I believe closely resembles } \\
\text { actual practice as a pharmacist where there is a big focus on } \\
\text { finding the information from the correct place rather than } \\
\text { memorising and rote-learning" }\end{array}$ \\
\hline
\end{tabular}

more than one node, it was coded to multiple nodes. Consensual validation of the final themes was reached through discussion, and the Cohen kappa coefficient was used to measure interrater reliability. Mean kappa coefficients for the three themes were $0.88(\mathrm{SD}=0.14)$ for the theme Exams, $0.84(\mathrm{SD}=0.08)$ for the theme Study, and $0.90(\mathrm{SD}=0.12)$ for the theme Role of the $A M H$.

Questions from fourth-year examinations (from both semesters and both years) were categorized as either a lower (understanding, comprehension) or higher (application, analysis, evaluation, synthesis) level of Bloom's taxonomy ${ }^{14-16}$ by an independent rater. The independent rater was not told on which examinations students had access to an $A M H$. Student performance in examinations in the first and second semesters was compared.

The student self-reported number of hours studied was analysed using a one-way analysis of variance (ANOVA) to determine whether there were any significant differences between number of hours studied during the time periods leading up to examinations, between the two semesters, or across the years. When there was a significant main effect, a post hoc Tukey multiple comparison test was performed to determine the specific time periods for which the differences were significant.

Statements about study approaches were grouped into categories (deep motive, deep strategy, surface motive, surface strategy) as reported by Biggs and colleagues. ${ }^{11} \mathrm{~A}$ two-way ANOVA was used to determine whether there were any self-reported differences in study approaches between the two semesters and years. Cronbach alpha values were used to measure the internal consistency for each group of statements.

Student performance in examinations in first and second semester courses was compared using a two-way ANOVA, with semester and year as between-subjects factors. A repeated measures ANOVA was used to 


\section{American Journal of Pharmaceutical Education 2021; 85 (1) Article 7990.}

compare the proportion of higher-level Bloom's taxonomy questions across examinations, with semester and year as between-subjects factors. A Holm-Sidak multiple comparison test was used to determine whether there was a significant difference in student performance between semesters of the same year.

\section{RESULTS}

Table 1 shows examination marks in seven courses for the two years of the study. There was no significant effect of year $\left(\mathrm{F}_{1,10}=.03, p=.86\right)$ or semester $\left(\mathrm{F}_{1,10}=\right.$ $.32, p=.58$ ) in terms of examination marks (Table 1$)$.

Questions from semester 1 and semester 2 examinations were evaluated using Bloom's taxonomy, where questions only requiring knowledge or comprehension were classified as lower-level Bloom's questions, and questions requiring application, analysis, synthesis, or evaluation were classified as higher-level questions in Bloom's taxonomy (Figure 1). A two-way ANOVA found a significant effect of semester (semester one or two) on Bloom's level $\left(\mathrm{F}_{1,5}=9.147, p<.05\right)$, but no significant effect of year (2015 or 2016) $\left(\mathrm{F}_{1,5}=2.018\right.$, $p>.05)$. A Holm-Sidak multiple comparison test revealed a significantly greater percentage of questions of high Bloom's level in semester two examinations in 2015 and in 2016 compared to semester one in the same respective year ( $p<.05$ in both years).

Information concerning the age and gender of the students who participated in the study and completed the surveys is shown in Table 2. Responses totalled 109, and ranged from three words, to paragraphs consisting of seven to eight sentences.

Regarding student comments on questions in the survey, in 2015 there were 29 text responses to the semester one survey and 41 responses to the semester two survey. In 2016, there were 20 text responses to the semester one survey and 19 responses to the semester two survey.

During the thematic analysis of 109 responses, 151 statements were coded. From these statements, three primary themes were identified: study, examinations, and the role of $A M H$. Within these themes, subthemes were identified. For "study," subthemes were "approaches to learning" (17 statements were identified that pertained to open book, 28 statements pertained to closed book), and "quantity and justification" (11 statements were identified that pertained to open book, 22 to closed book). For "exams," subthemes were "positive aspects" (4 statements were identified that pertained to open book, 1 for closed book), "negative aspects" (4 statements were identified that pertained to open book, 7 to closed book) and "thoughts of exam content" (11 statements were

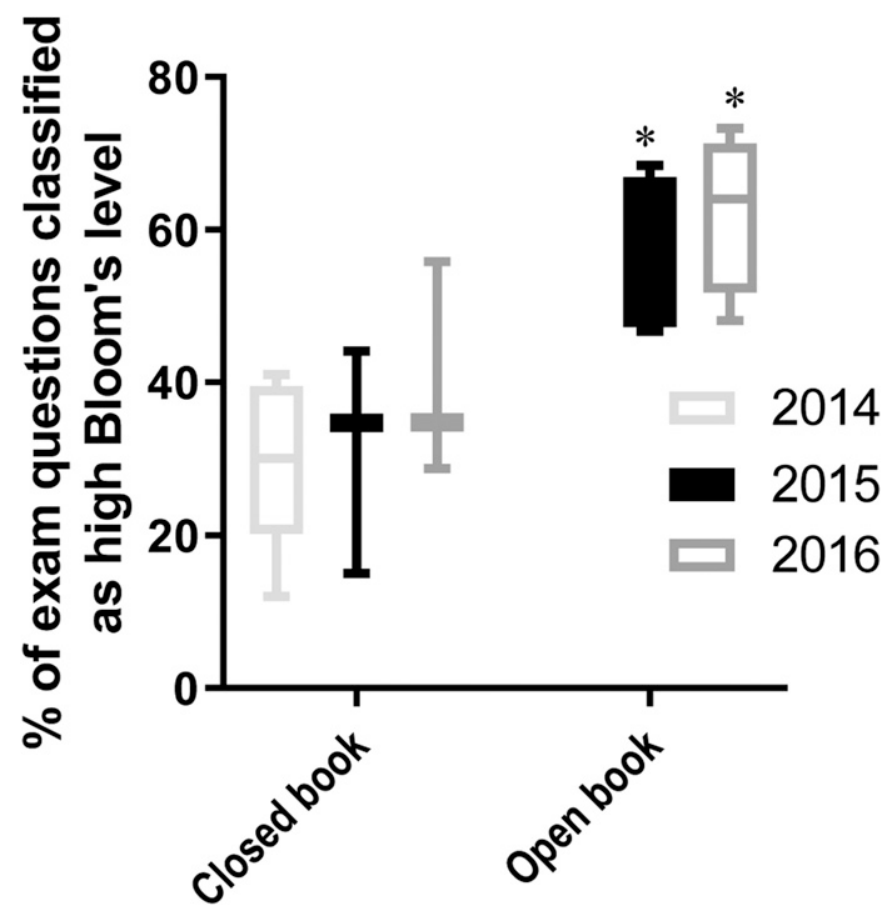

Figure 1. The Percentage of Examination Questions Classified as High on Bloom's Learning Scale

* Indicates $p<.05$ compared to closed book examinations in the same year. 2014 is included for comparison only.

identified that pertained to open book, 12 to closed book). For "role of $A M H$," subthemes were "positive aspects" (10 statements were identified that pertained to open book, 3 to closed book), "negative aspects" (10 statements were identified that pertained to open book, 2 to closed book) and "how $A M H$ was used" (5 statements were identified that pertained to open book, 4 to closed book). There were no significant differences with regards to self-reported hours of study between the 2015 and 2016 student cohorts, and no significant differences in the selfreported hours of study between first and second semester courses within a particular year. There was, however, a significant difference in terms of the reported number of hours spent studying per week that students reported across the different time periods during the semester $\left(\mathrm{F}_{65,508}=7.49, p<.001\right.$, Table 2). A post-hoc Tukey multiple comparison test revealed that students reported studying a significantly greater number of hours per week during the nonteaching week and examination period than they did during the first and last half of the semester $(p<.001$ for both years of the study).

Approximately half of the coded statements (78 of 151) related to study. There were 33 statements specifically related to "quantity and justification" that were coded to "time management." In student comments from first semester, a commonly expressed concern related to 


\section{American Journal of Pharmaceutical Education 2021; 85 (1) Article 7990.}

the perceived disruptive effects of the experiential placements upon study efforts.

Several students commented that their study efforts increased significantly towards the end of the semester and during the non-teaching week and examination period. There were three comments regarding semester two that pertained to the perceived disruptive effects of the intern pharmacist application process (for the following year) scheduled during the semester. As a result, students may have spent a considerable amount of time studying for and applying for internship positions rather than studying for their examinations.

There was no significant difference between types of study approaches between the two semesters $\left(\mathrm{F}_{1,368}=.05\right.$, $p>.05, \eta^{2}<.01$; Table 3 ) or between the two years (for example, deep approach $\mathrm{F}_{1,138}=.05, p>.05, \eta^{2}<.01$; Table 3).

Of the 151 coded statements, 44 specifically related to study approaches. Comments from students suggested that a major reason for adopting a greater surface approach to studying was because of time restrictions rather than because they did not find the material engaging.

Most questions regarding student examination experience did not significantly change between first and second semester (Table 4). A two-way ANOVA revealed that the only significant difference between first and second semester was student ratings of the statement "During my study, I frequently referred to an Australian Medicines Handbook $(A M H) "\left(\mathrm{~F}_{1,144}=17.2, p<.001\right)$. A Tukey multiple comparison test revealed that students more frequently used their $A M H$ while studying for second semester courses in $2015(p<.01)$ and $2016(p<.05)$, but there was no significant differences between students enrolled in the 2015 and 2016 cohorts.

Across both years of the study, $36 \%$ of students answered "Not at all" or "To a small extent" with regard to the statement "I prefer open book to closed book exams" in semester one; this percentage increased to $47 \%$ in semester two. Of note, $61 \%$ of students across both years of the study answered "to a large extent" or "all the time" to the statement, "Knowing that I will have access to the $A M H$ during the exam allowed me to pay less attention to remembering specific facts." Also, 68\% of students across both years of the study answered, "Knowing that I will have access to the $A M H$ during the exams allowed me to pay more attention to higher level skills such as analysis and evaluation."

Among the 151 comments referring to the examination, 39 encompassed positive aspects (5), negative aspects (11), or thoughts about the examinations (23). Students agreed that for courses where the $A M H$ was allowed in examinations, examination questions were of a higher Bloom's level.

Student comments revealed an appreciation that studying with the $A M H$ was beneficial for learning pharmacy information. While there was no significant effect of allowing the $A M H$ into examinations on self-reported student anxiety levels, some students clearly did believe their anxiety reduced as some student comments reported beneficial outcomes in terms of decreasing anxiety and stress.

\section{DISCUSSION}

This study reports on the impact of allowing fourthyear Bachelor of Pharmacy students at Monash University to use a medicines formulary during examinations. The primary purpose of permitting the use of a formulary in examinations was to emulate the real-world pharmacy environment. The $A M H$ (https://amh.net.au/), which is updated yearly, is a useful resource containing up-to-date medicines information, and this resource is commonly used by practicing pharmacists in Australia. An unrestricted open-book examination approach was eschewed (ie, allowing students to bring any materials), as it would have been difficult for some students to obtain multiple resources, raising equity issues.

Pharmacy student performance on open-book examinations where they were allowed to use a formulary was not affected compared with student performance on closed-book examinations (Table 1). Previous studies have reported either an improvement, ${ }^{5,9}$ decline in, ${ }^{10}$ or no effect ${ }^{17}$ on student performance on open-book tests as compared with performance on closed-book tests. In the present study, open-book examinations in semester two had a greater number of questions requiring higher-order cognitive skills than closed-book examinations in semester one, despite no specific directive given to course coordinators to change examination question types (Figure 1). Closed book examinations in 2015 and 2016 had a similar proportion of examination questions requiring higher-order cognitive skills than in 2014 (Figure 1). One intention of permitting students to bring a formulary into examinations was that it would encourage course coordinators to include a greater number of questions requiring the use of information from the $A M H$ to answer scenario-based questions more applicable to pharmacy practice. The observed outcome was the construction of examinations with a greater proportion of questions that addressed higher cognitive levels. This was consistent with the well-known fact that open-book examinations enable the assessment of higher-order cognitive abilities $^{18}$ as well as being consistent with results from the survey demonstrating that $\mathrm{AMH}-a$ allowed examinations tested higher-order cognitive thinking.

Allowing students to use a formulary in examinations did not decrease self-reported study time-on-task for final-year pharmacy students (Table 2). Penninga and colleagues proposed that students spend less time 


\section{American Journal of Pharmaceutical Education 2021; 85 (1) Article 7990.}

studying for open-book tests than closed-book tests because they considered closed-book tests to be more important, while they know they can consult their references if necessary in an open-book assessment. ${ }^{19}$ However, other studies show no difference in time-on-task studying between closed-book and open-book tests. ${ }^{20,21}$ As the $A M H$ does not contain all information required to successfully complete fourth-year pharmacy examinations, students still needed to study content that was not in the $A M H$ for the examinations, which may explain the lack of time-on-task differences in the present study. Alternatively, it may be that students were motivated to study as much for open-book as for closed-book examinations because the closed-book examinations were considered "high stakes" as a greater than $50 \%$ result was required to pass the course of study and finish their degree. Another possible reason for the equivalent self-reported times spent studying for $A M H$-allowed and closed-book examinations is that students in both years of the study were warned from the outset of the potential risk of relying too much on their $A M H$ in an examination. Finally, this equivalence in test performance may have been indicative of the fact that the fourth-year pharmacy students were in their final year and had an established study regimen. Future work should investigate these possibilities through pre- and post-examination interviews. Considering there were only three examinations in semester one but four examinations in semester two, the number of hours students spent studying may have been greater in semester two.

Previous studies have shown that a deep learning approach is positively correlated with examination performance, while a surface learning approach is negatively correlated with examination performance. ${ }^{22}$ In terms of student self-reported study approaches as measured in the current investigation, there were higher mean scores for "deep approach" than for "surface approach" across both semesters, although there were no significant differences between study motives, strategies, or approaches to study within or between the two semesters (Table 3). Given that fourth-year pharmacy students were being assessed, it is likely that their study approaches are well established by this time, resulting in the lack of variability between semesters one and two in both years. Students with deep approaches to learning have been shown to perform better on both open- and closed-book examinations. ${ }^{18}$ It would be valuable to test this relationship, but because of the anonymous nature of the surveys, a student-specific comparison between learning approach and examination outcomes was not possible, which is a limitation of the current study.

Contrary to previous studies, ${ }^{4,21}$ allowing the use of the $A M H$ in examinations had no significant effect on the self-reported anxiety levels of the respondents (Table 4). This could be because of the fact that students had four examinations in the second semester compared with three in the first semester. Also, comments collated from students in both years indicated that many were unhappy with the scheduling of the semester two examinations, whereby two examinations were held on consecutive days. Students generally report feeling anxious prior to and during examinations ${ }^{23}$; thus, having a greater number of examinations and poorer scheduling of them in semester two likely impacted student anxiety levels. In addition, several students commented that during semester two, they had the added stress of interviews for hospital internship positions for their following year. Several student comments indicated a perceived benefit of formulary-allowed examinations, with students reporting a lower level of anxiety both prior to and during examinations. However, given the small sample size, it would not be appropriate to generalize across the whole student cohort.

As alluded to above, another limitation of the study was small sample sizes, particularly in semester two in 2016. This may be why the Cronbach alpha value for "examination satisfaction" was 0.3 (Table 4). There was also a low Cronbach alpha value (0.3) for the 2015 cohort for statements 11 and 12 (Table 4). This may have indicated poor interrelatedness between these two items. ${ }^{24}$ Given the low response rate, student survey data should not be used to draw definitive conclusions, and it is acknowledged that given the low response rate, the students who did respond may not be reflective of the whole cohort. Another limitation is that courses from semester one were compared with courses from semester two, meaning that some effects (or lack thereof) may have been because of the variability in time of testing. It would have been useful to compare courses within each semester to control for this; however, we thought that having some examinations in which use of a formulary was allowed and some in which it was not in the same semester could have caused confusion for students and resulted in a lesser amount of study for courses where the formulary was allowed in the examination. A further limitation is that students were asked to recall the number of hours they studied after the semester was finished, which may have led to recall bias.

\section{CONCLUSION}

With the exponential increase in medical knowledge occurring around the world, pharmacy schools must assess students on their ability to find, analyze, and apply information, rather than only on their ability to recall and understand information. The present study demonstrates 


\section{American Journal of Pharmaceutical Education 2021; 85 (1) Article 7990.}

how allowing students to use a medicines formulary during examinations enables course coordinators to test students on more cognitively challenging questions without a corollary decrease in examination performance. Self-reported study habits (time-on-task or approach), anxiety levels, and learning motivations or strategies also were not affected. However, students reported using their medicines formulary more to study for end-of-semester examinations when use of the formulary was permitted in the examination. This research has led to the continual use of the $A M H$ in some pharmacy examinations at Monash University.

\section{ACKNOWLEDGMENTS}

The authors thank Dr. Somaiya Naidu and Dr. Sheryl Maher for thoughtful discussions regarding study development, and Nicole Eise for categorizing examination questions.

\section{REFERENCES}

1. Eilertsen TV, Valdermo O. Open-book assessment: a contribution to improved learning? Stud Educ Eval. 2000;26(2):91-103.

2. Tussing L. A consideration of the open book examination. Educ Psychol Meas. 1951;11:597-602.

3. Stalnaker JM, Stalnaker RC. Open-book examinations. J Higher Ed. 1934;5(3):117-120.

4. Feller M. Open-book testing and education for the future. Stud Educ Eval. 1994;20(2):235-238.

5. Gharib A, Phillips W, Mathew N. Cheat sheet or open-book? a comparison of the effects of exam types on performance, retention, and anxiety. Psychol Res. 2012;2:469-478.

6. Williams JB, Wong A. The efficacy of final examinations: a comparative study of closed-book, invigilated exams and open-book, open-web exams. Br J Educ Tech. 2009;40(2):227-236.

7. Broyles IL, Cyr PR, Korsen N. Open book tests: assessment of academic learning in clerkships. Med Teach. 2005;27(5):456-462.

8. Densen P. Challenges and opportunities facing medical education. Trans Am Clin Climatol Assoc. 2011;122:48-58.

9. Ramamurthy S, Er HM, Nadarajah VD, Pook PCK. Study on the impact of open and closed book formative examinations on pharmacy students' performance, perception, and learning approach. Curr Pharm Teach Learn. 2016;8(3):364-374.

10. Heijne-Penninga M, Kuks JB, Schonrock-Adema J, Snijders TA, Cohen-Schotanus J. Open-book tests to complement assessmentprogrammes: analysis of open and closed-book tests. Adv Health Sci Educ. 2008;13(3):263-273.
11. Biggs JB, Kember D, Leung DYP. The revised two-factor study process questionnaire: R-SPQ-2F. Br J Ed Psychol. 2001;71(1):133-149. 12. Malczewska-Webb B, Nowacka M, Ong S. Research approaches and student surveys: a cross-cultural perspective. In: Gabryś-Barker D, Wojtaszek A, eds. Studying Second Language Acquisition from a Qualitative Perspective. Vol 27: Springer International Publishing; 2014:127-143.

13. Braun V, Clarke V. Using thematic analysis in psychology. Qual Res Psychol. 2006;3(2):77-101.

14. Anderson LW, Krathwohl DR, Airasian PW, et al. A taxonomy for learning, teaching, and assessing: A revision of Bloom's taxonomy of educational objectives. In Anderson L.W. \& Krathwohl D.R. (Eds.) The role of assessment in the revised taxonomy (pp. 249254). New York: Addison Wesley Longmann; 2001.

15. Bloom BS, Engelhart MD, Furst EJ, Hill WH, Krathwohl DRA. Taxonomy of educational objectives: The classification of educational goals; Handbook I: Cognitive Domain. New York: Longmans, Green; 1956.

16. White PJ, Larson I, Styles K, et al. Adopting an active learning approach to teaching in a research-intensive higher education context transformed staff teaching attitudes and behaviours. High Educ Res Dev. 2016;35(3):619-633.

17. Sato BK, He W, Warschauer M, Kadandale P. The grass isn't always greener: perceptions of and performance on open-note exams. CBE Life Sci Educ. 2015;14(2).

18. Heijne-Penninga M, Kuks JBM, Hofman WHA, CohenSchotanus J. Influences of deep learning, need for cognition and preparation time on open- and closed-book test performance. Med Educ. 2010;44(9):884-91.

19. Heijne-Penninga M, Kuks JBM, Hofman WHA, CohenSchotanus J. Influence of open- and closed-book tests on medical students' learning approaches. Med Educ. 2008;42(10):967-974.

20. Myyry L, Joutsenvirta T. Open-book, open-web online examinations: developing examination practices to support university students' learning and self-efficacy. Act Learn High Educ. 2015;16(2):119-132.

21. Theophilides C, Koutselini M. Study behavior in the closed-book and the open-book examination: a comparative analysis. Educ Res Eval. 2000;6(4):379-393.

22. May W, Chung E-K, Elliott D, Fisher D. The relationship between medical students' learning approaches and performance on a summative high-stakes clinical performance examination. Med Teach. 2012;34(4):e236-e41.

23. Gregor A. Examination anxiety: live with it, control it or make it work for you? Sch Psychol Int. 2005;26(5):617-635.

24. Tavakol M, Dennick R. Making sense of Cronbach's alpha. Int $J$ Med Educ. 2011;2:53-55. 